\title{
Oral mucoceles: A clinical, histopathological and immunohistochemical study
}

\author{
Jamile Gomes Conceição ${ }^{a}$, Clarissa Araújo Gurgel ${ }^{\mathrm{a}, \mathrm{b}}$, Eduardo Antônio Gonçalves Ramos ${ }^{\mathrm{a}, \mathrm{c}}$, \\ Flávia Caló De Aquino Xavier ${ }^{\mathrm{b}}$, Caroline Brandi Schlaepfer-Sales ${ }^{\mathrm{a}}$, Maria Cristina Teixeira Cangussu ${ }^{\mathrm{d}}$, \\ Patrícia Ramos Cury ${ }^{\mathrm{e}}$, Luciana Maria Pedreira Ramalho ${ }^{\mathrm{f}}$, Jean Nunes Dos Santos ${ }^{\mathrm{a}, \mathrm{b}, *}$ \\ a Postgraduate Program in Human Pathology, Oswaldo Cruz Foundation, Salvador, Bahia, Brazil \\ ${ }^{\mathrm{b}}$ Laboratory of Oral Surgical Pathology, School of Dentistry, Federal University of Bahia, Salvador, Bahia, Brazil \\ ${ }^{\mathrm{c}}$ Laboratory of Pathology and Biology Molecular, Oswaldo Cruz Foundation, Salvador, Bahia, Brazil \\ ${ }^{d}$ Department of Dental Public Health, School of Dentistry, Federal University of Bahia, Salvador, Bahia, Brazil \\ e Department of Periodontics, School of Dentistry, Federal University of Bahia, Salvador, Bahia, Brazil \\ ${ }^{\mathrm{f}}$ Department of Stomatology, School of Dentistry, Federal University of Bahia, Salvador, Bahia, Brazil
}

\section{A R T I C L E I N F O}

\section{Article history:}

Received 16 March 2013

Received in revised form 17 April 2013

Accepted 28 April 2013

\section{Keywords:}

Oral mucoceles

Histopathology

Myxoglobulosis

Immunohistochemistry

\begin{abstract}
A B S T R A C T
The aim of study was to evaluate the clinicopathological features of oral mucoceles and the immunohistochemical expression of cellular and extracellular matrix components in these lesions. One hundred cases of oral mucoceles were examined for clinicopathological features. The expression of mast cell tryptase, CD68, MMP-1 (matrix metalloproteinase-1), MMP-9 (matrix metalloproteinase-9) and CD34 was investigated immunohistochemically in 32 cases. The lesions arose as nodules or blisters of variable color. The mean age was 23.2 years and a higher male frequency was observed. The most common locations were the lower lip (92\%), followed by the floor of the mouth (7\%), and palate (1\%). The lesion size ranged from 0.4 to $3.0 \mathrm{~cm}$. Unusual histopathological findings as superficial mucoceles ( $n=16,16 \%)$, pseudopapillary projections $(n=3,3 \%)$, epithelioid histiocytes $(n=4,4 \%)$, multinucleated giant cells $(n=1,1 \%)$ and myxoglobulosis $(n=9,9 \%)$ were also seen. Mast cells and CD68-positive macrophages, MMP-1, MMP-9 and CD34-positive blood vessels were seen in all cases. A significant association was seen between mast cells and MMP-1 $(p=0.03)$ and between macrophages and MMP-1 $(p=0.01)$. This study provided important insight into the demographic and histopathological occurrence of oral mucoceles. The tissue remodeling seen in these lesions mainly involved the migration and interaction of mast cells, macrophages and MMP-1.
\end{abstract}

(c) 2013 Elsevier GmbH. All rights reserved.

\section{Introduction}

Oral mucoceles are benign lesions that can appear as blisters or lumps at any site of the oral cavity where minor salivary glands are present. Their etiology is associated with local trauma and consequent rupture of salivary gland ducts, especially in the lower lip. These events lead to mucus accumulation in connective tissue and trigger an inflammatory reaction characterized by the formation of granulation tissue (Li et al., 1997; Hayashida et al., 2010). Granulation tissue involves proliferation of fibroblasts, deposition of collagens and other extracellular matrices and development of new blood vessels ( Li et al., 2007; Romana-Souza and Monte-Alto-Costa, 2010).

Angiogenesis plays an important role in tissue remodeling since it provides oxygen and nutrients to metabolically active cells and

\footnotetext{
* Corresponding author at: Laboratório de Patologia Cirúrgica, UFBA Avenida Araújo Pinho, 62, Canela, Salvador, Bahia 40110-150, Brazil.

E-mail address: jeanpatol@gmail.com (J.N. Dos Santos).
}

contributes to the continuous recruitment of inflammatory cells and mediators to the site of injury (Tonnesen et al., 2000). According to Swelam et al. (2005), newly formed capillaries are also present in mucous retention cysts as CD34-positive blood vessels.

Mast cells are bone marrow-derived cells that participate in the response to cell injury, angiogenesis, tissue remodeling and collagen production (Enoksson et al., 2011) and sustain the development of granulation tissue (Romana-Souza and Monte-Alto-Costa, 2010). There are no reports in the literature on the role of mast cells in oral mucoceles, but studies have shown that in an inflammatory environment these cells produce factors that induce vascular alterations, and promote the recruitment of inflammatory cells to the site of injury (Metcalfe et al., 1997; Enoksson et al., 2011). Furthermore, mast cells secrete proteases and have been associated with fibrosis and chronic immune responses (Tefferi, 2005).

Macrophages are important cells involved in phagocytosis, in the functional modulation of different cell types and in the release of proinflammatory mediators such as matrix metalloproteinases (MMPs). In oral mucoceles, macrophages play a key role in the phagocytosis of mucus (Frederic et al., 2008; Chi et al., 2011). 
MMPs are important proteases that participate in tissue remodeling and angiogenesis. MMP-1, or collagenase, degrades collagen fibrils, whereas MMP-9 degrades non-fibrillar collagen and, together with other MMPs, establishes conditions for the migration and proliferation of new blood vessels, thus contributing to the process of angiogenesis (Parks, 1999). The development of oral mucoceles may therefore be related to the synergistic effect of MMPs in these lesions (Hoque et al., 1998; Pesce et al., 2003; Swelam et al., 2005).

Despite the frequent introduction of this topic in clinical practice, the mechanism by which cellular and extracellular matrix components participate in the formation of oral mucoceles has been little explored (Hoque et al., 1998; Pesce et al., 2003; Swelam et al., 2005). The aim of this study was to evaluate the clinical-pathological profile of oral mucoceles and to discuss their immunohistochemical profiles for mast cell tryptase, CD-68, MMP1, MMP-9 and CD-34.

\section{Materials and methods}

After approval of the study by the Ethics Committee of the School of Dentistry, Federal University of Bahia (FOUFBA), 100 cases of extravasation mucoceles seen between 2002 and 2010 and retrieved from the archives of the Pathological Anatomy Service of FOUFBA, were submitted to histological analysis and histochemistry using picrosirius red staining method. Thirty-two of these cases were used for immunohistochemical study. Clinical data such as gender, age, location of the lesion, color, size, consistency, shape, clinical suspicion and possible etiological agent were collected from the corresponding findings.

For immunohistochemistry, 3- $\mu \mathrm{m}$ thick sections were cut from each paraffin block and deparaffinized in two xylene baths for 15 min each. Next, the sections were rehydrated in absolute alcohol twice ( 5 min each) to distilled water. Table 1 shows the primary antibodies, clones, dilutions, antigen retrieval, and positive controls used. Endogenous peroxidase was blocked by incubation in $3 \%$ hydrogen peroxide for $15 \mathrm{~min}$. The sections were incubated with the primary antibody diluted in antibody diluent in addition to background-reducing components (Dako Corporation, Carpinteria, CA, USA) at room temperature for $1 \mathrm{~h}$. The Envision polymer (Dako), prepared according to manufacturer's instructions, was then applied for $30 \mathrm{~min}$ at room temperature, followed by the development of the reaction with 3,3-diaminobenzidine (DAB; Dako) as chromogen solution for $5 \mathrm{~min}$ in a dark chamber. The sections were counterstained with Mayer's hematoxylin. Finally, the sections were dehydrated in absolute alcohol, cleared in xylene, and mounted. In the negative control the primary antibody was replaced with non-immune serum.

Histomorphometric assessment was carried out under a highresolution light microscope at $400 \times$ magnification (Zeiss Axiostar plus, Göttingen, Germany). Up to 10 fields, in each case, were analyzed and the images were recorded with a digital camera (Zeiss Axiocam ICC3) using specific software (Zeiss Axiovision ver. 4.8). The density of mast cells and macrophages was expressed as the mean number of positive cells in an area of $56 \mu \mathrm{m} / \mathrm{mm}^{2}$ at $200 \times$ magnification.

The immunostaining of MMP-1 and MMP-9 was classified in each case as 0 (no staining), $+(<10 \%$ of stained cells $),++(10-50 \%$ of stained cells) or $+++(>50 \%$ of stained cells $)$.

Microvessel density was determined in areas of granulation tissue containing a large number of stained microvessels and expressed as a percentage of the mean number of vessels per area $\left(56 \mu \mathrm{m} / \mathrm{mm}^{2}\right)$ at $200 \times$ magnification.

Collagen fiber deposition (fibrosis) as a result of the lesion was detected by picrosirius red staining (Coleman, 2011). The specimens were analyzed under a light microscope by an experienced pathologist (J.N.S). The presence of collagens was classified semiquantitatively in each case as 0 (no fibrosis), + (mild fibrosis), ++ (moderate fibrosis) or +++ (intense fibrosis).

Statistical analysis was performed using the Minitab program (Belo Horizonte, Minas Gerais, Brazil). Differences between groups were evaluated by the non-parametric Kruskal-Wallis test. Pearson's correlation test was also used between markers. A $p$ value of less than 0.05 was considered significant.

\section{Results}

Among the 100 cases of oral mucocele cases studied, 60 (60\%) came from males and 40 (40\%) from females, corresponding to a ratio of $1.5: 1$. Peak incidence occurred equally in the second and third decades of life, accounting for more than $50 \%$ of all cases. Patient age ranged from 1 to 57 years (mean \pm standard deviation: $23.2 \pm 12.24$ years).

Clinically, the lesions appeared as nodules or blisters of variable color and predominantly elastic consistency. Mucocele was the clinical diagnosis in 79 cases (79\%) and ranula in 10 (10\%), followed by fibroma $(n=5)$, cystadenoma $(n=1)$, and five cases presented no information. Most lesions were located in the lower lip (92\%), followed by the floor of the mouth (7\%) and palate (1\%). A history of trauma was reported by 11 patients, including bites in four. The size of the lesion ranged from 0.4 to $3.0 \mathrm{~cm}(1.1 \pm 0.57 \mathrm{~cm})$ (Fig. 1). All cases were treated by surgical removal.

In general, the mucoceles had a nodular and eventually polypoid structure and they were lined with squamous keratinized epithelium exhibiting acanthosis with or without reactional atypias. In addition, atrophy was observed in superficial lesions. A band of lamina propria separating the lesions was seen in some cases, whereas no surface epithelium was present in others. Ulceration was observed in only one case.

There were single or multiple lesions among the studied cases (Fig. 2a). The lesions were formed by a wall of granulation tissue $(n=92,92 \%)$ which was thin $(n=11,11 \%)$, thick $(n=25,25 \%)$ or variable in thickness $(n=51,37 \%)$. It was often surrounded by a fibrous band, here called a fibrous capsule. In some cases, these cavities had collapsed and no cystic structures were observed $(n=69$, $69 \%$ ). Granulation tissue was found to be scattered throughout the lamina propria, located superficially or near proteinaceous or amorphous material. At times, it was seen distending the proteinaceous

Table 1

Antibodies used in immunohistochemical analysis.

\begin{tabular}{|c|c|c|c|c|c|}
\hline Primary antibody & Clone & Antigen retrieval & Dilution & Incubation & Source \\
\hline CD34 & QBend-10 & Citrate buffer pH 6.4 a $97^{\circ} \mathrm{C}$ & $1: 100$ & $60 \min$ & DAKO \\
\hline Mast cell tryptase & AA1 & Trypsin $1 \% 37^{\circ} \mathrm{C}$ & $1: 50$ & $60 \mathrm{~min}$ & NOVO CASTRA $* *$ \\
\hline CD-68 & KP1 & Citrate buffer pH 6.4 a $97^{\circ} \mathrm{C}$ & $1: 100$ & $60 \mathrm{~min}$ & DAKO $^{*}$ \\
\hline MMP-1 & Polyclonal & Citrate buffer $\mathrm{pH} 6.4$ a $97^{\circ} \mathrm{C}$ & $1: 50$ & Overnight & $\mathrm{DBS}^{* * *}$ \\
\hline MMP-9 & Polyclonal & None & $1: 50$ & $60 \mathrm{~min}$ & $\mathrm{DBS}^{* * *}$ \\
\hline
\end{tabular}

* Dako Corporation, Carpinteria, CA, USA.

** Leica Biosystems Newcastle Ltda, New Castle, UK.

*** Diagnostic Biosystems, Pleasanton, CA, USA. 

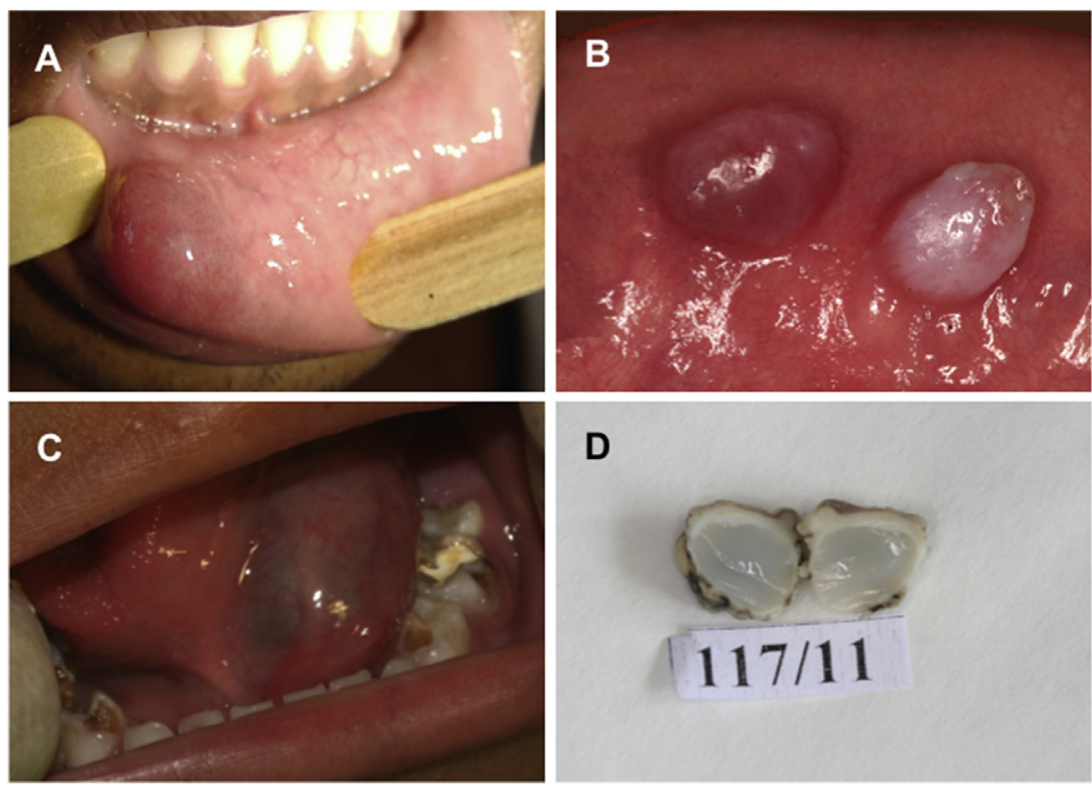

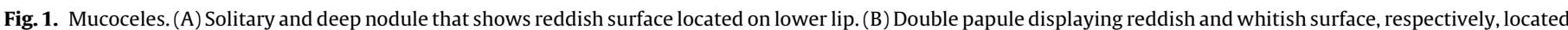

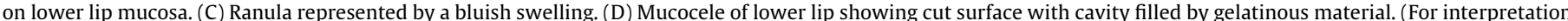
of the references to color in text, the reader is referred to the web version of this article.)

material or the collagen fibers or being interspersed among the extravasated red blood cells. In other cases, the lesions presented as cystic structures lined by granulation tissue, which was found to be scattered or arranged in nodular structures. Sixteen (16\%) of all cases were histologically superficial mucoceles.

The granulation tissue consisted of fibroblasts, new capillaries and mononuclear $(n=61,61 \%)$ or mixed ( $n=29,29 \%$ ) leukocytes. Accumulation of macrophages close to the lumen was frequently observed. The granulation tissue also exhibited pseudopapillary projections $(n=3)$ or tufts projecting into the lumen (Fig. $2 \mathrm{~b}$ ), and they appeared to have detached from the cystic wall floating freely in the lumen. In some cases, epithelioid histiocytes $(n=4)$ were observed close to the luminal surface (Fig. 2c). Macrophages eventually differentiated into epithelioid or multinucleated giant cells, eliciting a granulomatous reaction $(n=1)$ (Fig. 2d). Ductal epithelium was seen to be in close contact with the wall of granulation tissue and appeared to have arisen from duct rupture. The cystic lumen, if present, contained proteinaceous material ( $48 \%$ of cases) among numerous muciphages (45\% of cases). Polymorphonuclear leukocytes and clumps of proteinaceous material and amorphous
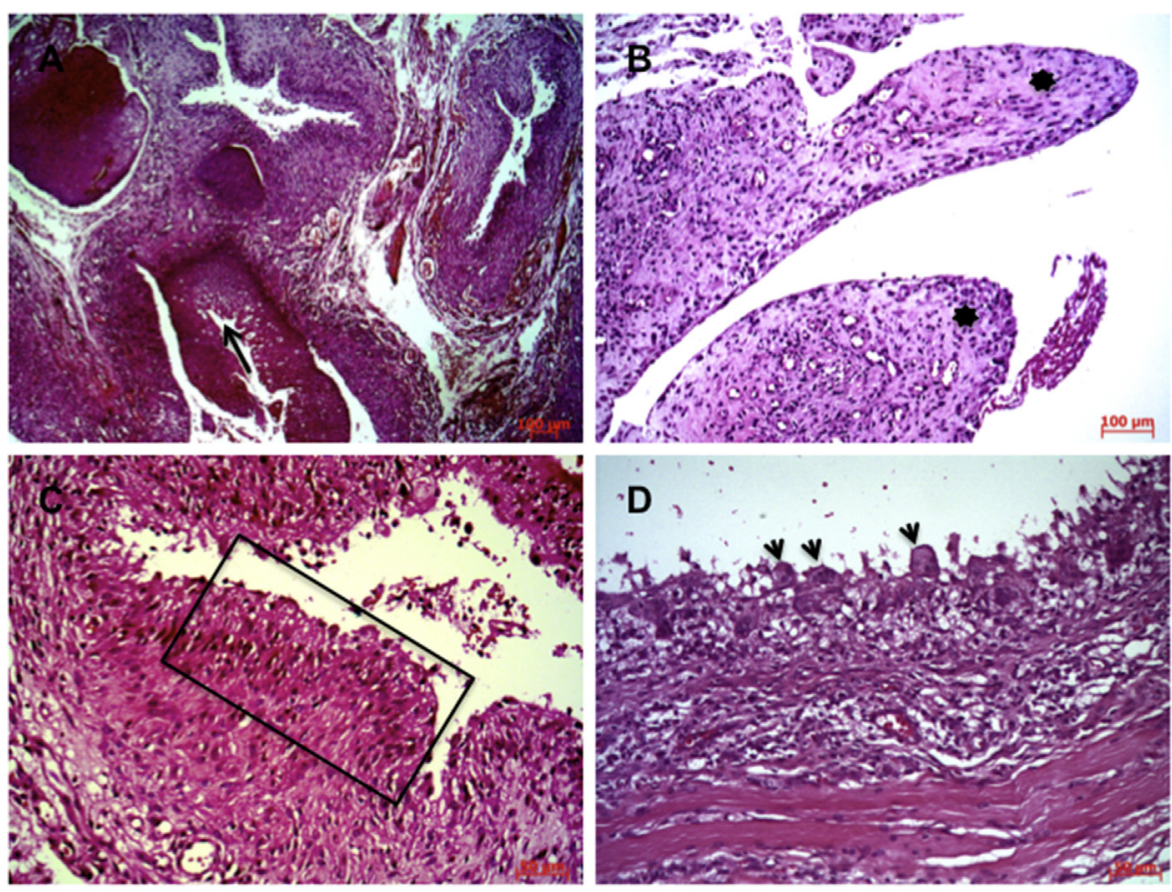

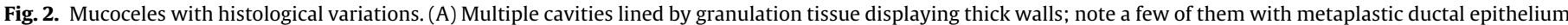

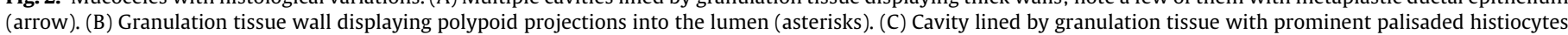
(rectangle). (D) Granulation tissue wall at which multinucleated giant cells (arrows) line the pseudocystic cavity. Scale bars: $A=200 \mu m$; $B=100 \mu m$; $C$ and $D=50 \mu m$. 


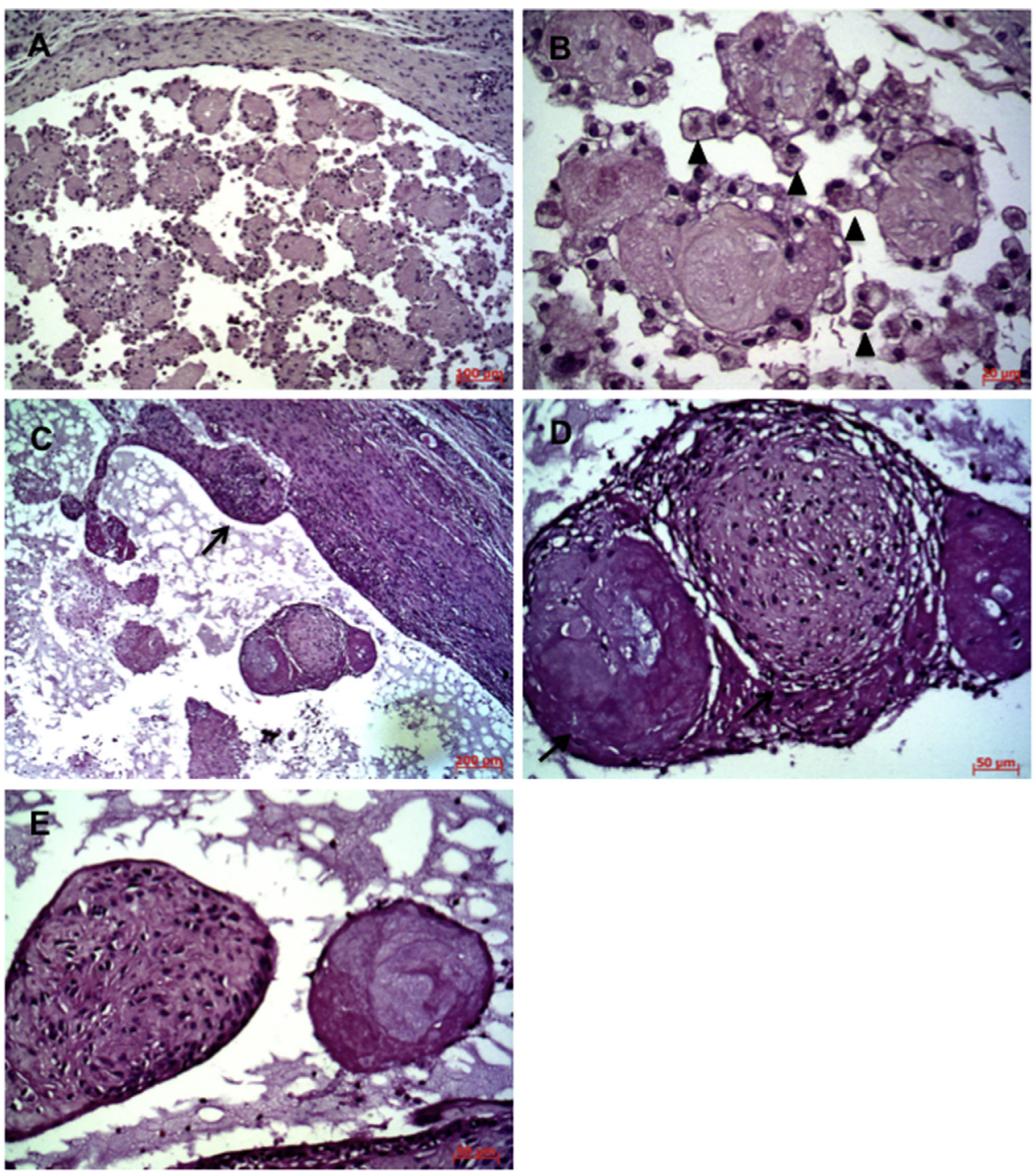

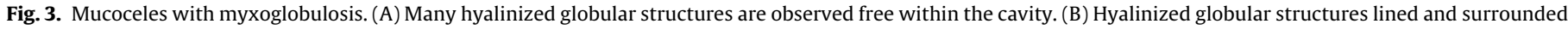

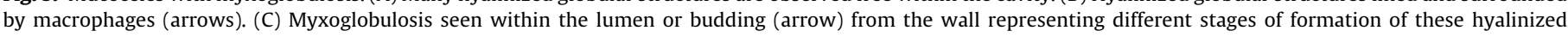

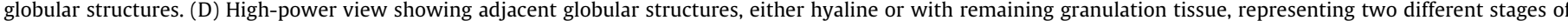

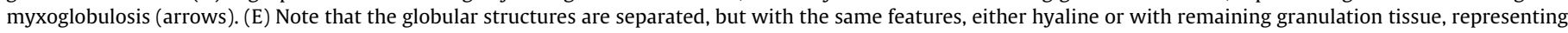
two different stages of myxoglobulosis previously described. Scale bars: $A=100 \mu \mathrm{m} ; B=20 \mu \mathrm{m} ; C=200 \mu \mathrm{m} ; \mathrm{D}$ and $E=50 \mu \mathrm{m}$.

or mucoid material were frequently observed. A less frequent finding was the presence of spherulosis, also called myxoglobulosis ( $n=9,9 \%$ ), showing different stages of formation (Fig. 3). Lobules consisting of mucous acini and glandular ducts $(n=81,81 \%)$ that were ectatic ( $n=66,66 \%)$ or metaplastic ( $n=37,37 \%)$, were commonly seen, as well as metaplastic glandular ducts with papillary projections. In some cases, the adjacent glandular tissue was permeated by a chronic inflammatory infiltrate $(n=19,19 \%)$.

The granulation tissue was generally less pronounced in lesions clinically defined as ranulas when compared to lip mucoceles. These ranula lesions were characterized by a fibrous or loose thick wall, hemorrhagic interstitial foci and scarce luminal proteinaceous material. Muciphages were rare. Adjacent glandular tissue showed normal features.

Mast cells were identified in all specimens studied. These cells had a variable shape, mainly round, and were found in granulation tissue of the cystic wall close to blood vessels. Accumulation of mast cells was seen in the capsular fibrous bands present in some lesions. As they approached the lumen, mast cells declined in number or even disappeared (Fig. 4a). Mast cells were rare in scattered granulation tissue. However, these cells were also detected in well-differentiated glandular tissue with or without inflammation. Mast cell numbers ranged from 3.8 to 57.2 $(57.2 \pm 1.1)$.

CD68-positive macrophages were detected in all cases. These cells mainly had a round or vacuolar shape and contained coarse brown granules. The cells were concentrated in the lumen and on the luminal surface, but were also found in the wall of granulation tissue (Fig. 4a-d). The number of macrophages ranged from 29.6 to $144.3(86.2 \pm 3.6)$

Variable MMP-1 and MMP-9 immunostaining was observed in 32 cases (Fig. 5). Immunostaining was observed in the extracellular matrix and granular staining was seen particularly in the capsular fibrous band, if present. Fibroblasts, inflammatory cells and muciphages were also positive for the two markers. With respect to MMP-1, most cases were scored as $+(n=17,53 \%)$, followed by $++(n=11,34.37 \%)$ and $+++(n=3,9.37 \%)$. No staining was seen in one case (3.12\%). Regarding MMP-9, most cases were scored as +++ 

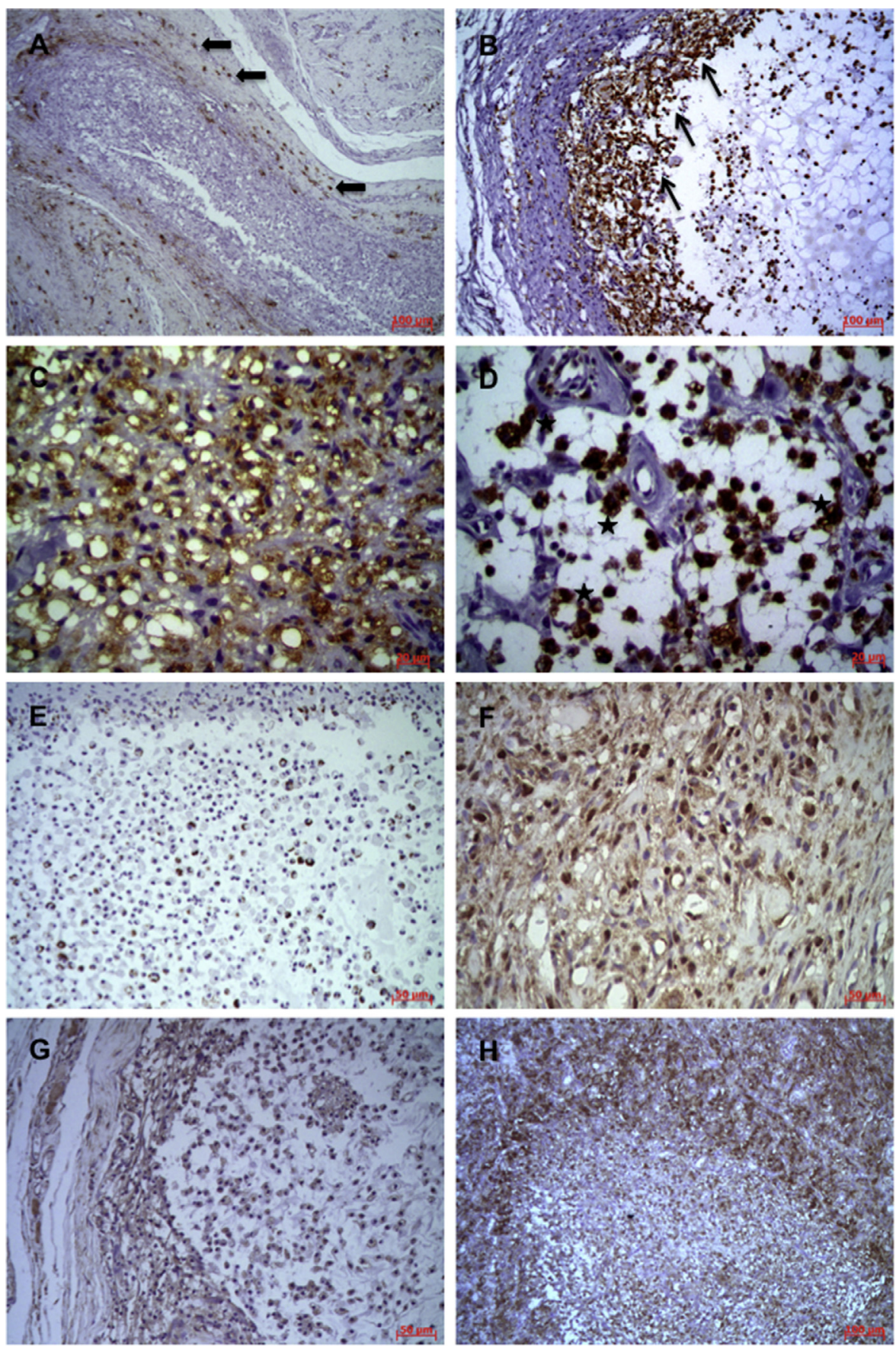

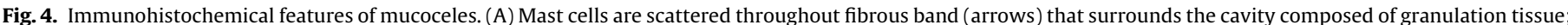

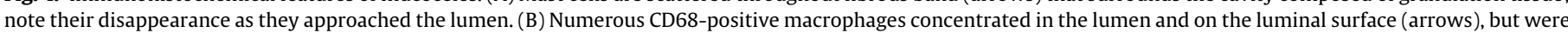

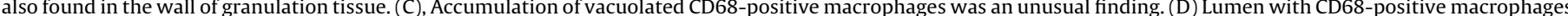

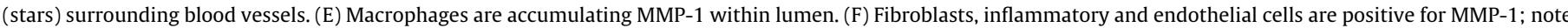

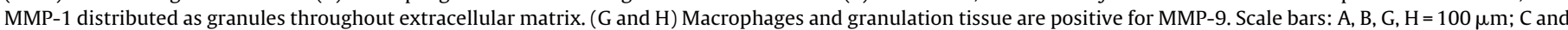
$\mathrm{D}=20 \mu \mathrm{m} ; \mathrm{E}$ and $\mathrm{F}=50 \mu \mathrm{m}$.

$(n=11,32.4 \%)$ and $++(n=11,32.4 \%)$. Scores of $+(n=8,25 \%)$ and 0 ( $n=2,6.25 \%)$ were less frequent.

All specimens were stained with the anti-CD34 antibody. However, CD34-positive blood vessels seemed to disappear with decreasing distance from the lumen. Analysis of the angiogenic index showed a microvessel density ranging from 21.2 to 160.4 microvessels per $\mathrm{mm}^{2}(68.12 \pm 3.1$ microvessels per $\mathrm{mm}^{2}$ ).

Picrosirius red staining revealed the presence of collagen fibers in 77 cases. Staining ranged from absent to intense. Mild fibrosis was observed in 35 (45.4\%) cases, moderate fibrosis in 28 (36.3\%), and intense fibrosis in 14 (18.2\%).

No significant association was observed between the different cellular and extracellular matrix components analyzed separately or together ( $p>0.05$, Kruskal-Wallis test). However, a significant association was seen between mast cells and MMP$1(p=0.03$, Kruskal-Wallis test) and between macrophages and MMP-1 ( $p=0.01$, Kruskal-Wallis test). There was no correlation between clinical data and the markers studied ( $p>0.05$, Pearson's test). 

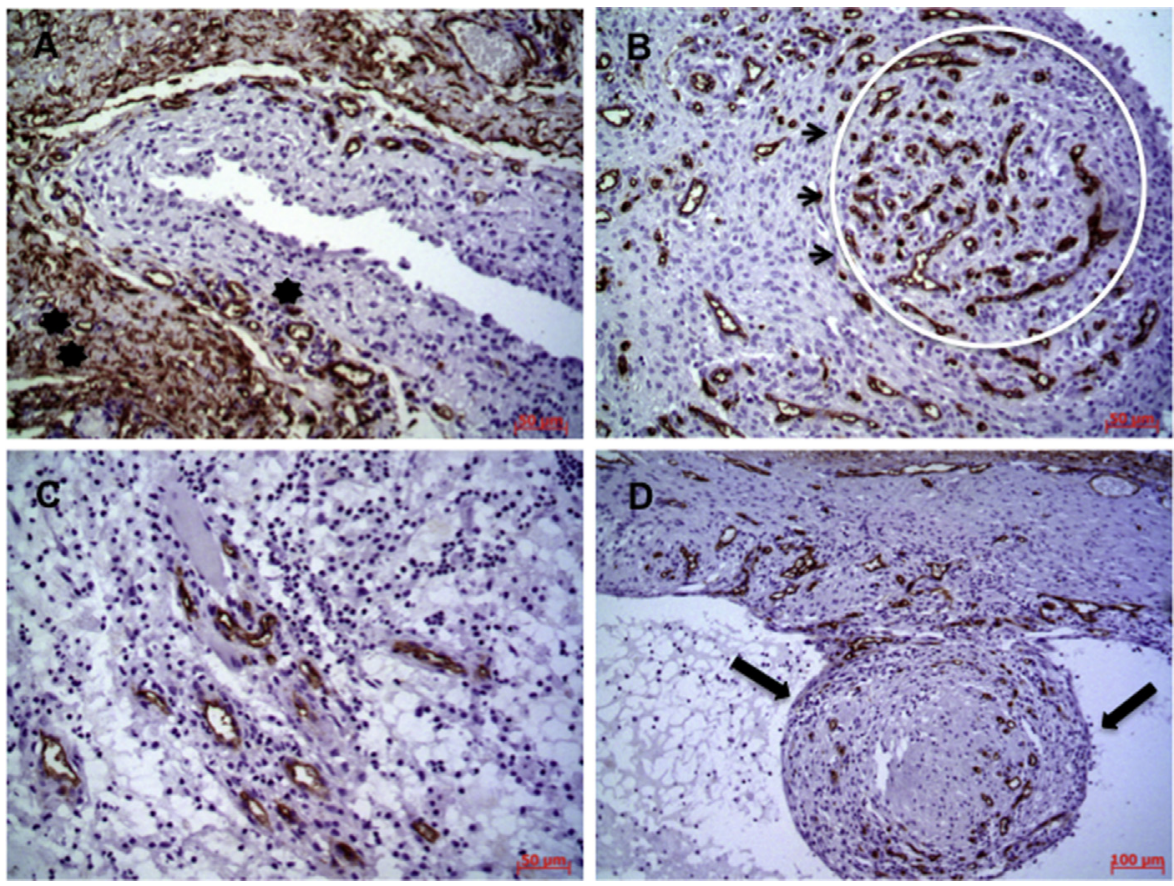

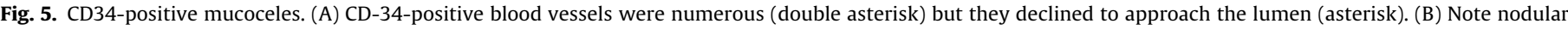

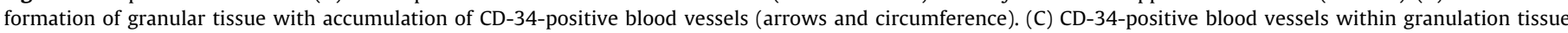

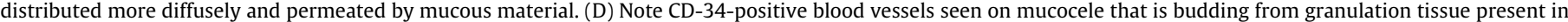
another mucocele (arrows). Scale bars: $A-C=50 \mu \mathrm{m} ; \mathrm{D}=100 \mu \mathrm{m}$.

\section{Discussion}

This study showed that oral mucoceles represent common lesions and clinical findings are similar to previous studies. However, they may exhibit great histological diversity. Furthermore, immunohistochemical profiles of cellular components and extracellular structures could contribute to our understanding the tissue remodeling of these lesions.

In the present series, mucoceles occurred more frequent among men, in agreement with some authors (Chen et al., 2010), however, other authors have reported predominance among females (Hayashida et al., 2010). The peak incidence occurred equally in the second and third decades of patient life in agreement with Hayashida et al. (2010). Other studies have reported a higher frequency among subjects in their 20s or younger (Chen et al., 2010; Chi et al., 2011). Mucoceles may also be congenital or arise soon after birth, but are rare in children less than 1 year of age (Nico et al., 2008). We found a mucocele in a child aged 1.8 years.

The mucoceles studied here appeared as blisters or nodules of variable color. Similar findings have been previously reported, with these lesions exhibiting a smooth surface, being asymptomatic and their color ranging from pink and blue to translucent and white (Nico et al., 2008; Ata-Ali et al., 2010).

Histologically, the mucoceles studied fulfilled the morphological criteria described in previous reports (Ide and Kusama, 2002; Frederic et al., 2008; Chi et al., 2011). In general, the lesions appeared as nodular cystic structures formed by a wall of granulation tissue rich in leukocytes often surrounding lumina filled with numerous muciphages amidst proteinaceous material. The observation of a band of fibrous and dense connective tissue surrounding lesions with a cystic structure agrees with previous investigations (Horie et al., 1993; Li et al., 1997; Ide and Kusama, 2002; Baurmash, 2003; Frederic et al., 2008). Proteinaceous material and variable numbers of macrophages and muciphages, as well as other inflammatory cells particularly neutrophils, were observed in the cystic lumina.
Another interesting finding of the present study was the projection of the granulation tissue walls into the lumina, which appeared to have detached from the cystic walls. This projection supports the hypothesis of Chi et al. (2011) and Ide and Kusama (2002), who attributed its occurrence to the origin of myxoglobulosis, in the lumina. However, the factors that lead to the transformation of mucus into these globular masses remain unknown ( $\mathrm{Li}$ et al., 1997). Myxoglobulosis is characterized by rare single globular structures with calcification and no epithelial linings which contain eosinophilic fibrillar material, sometimes phagocytosed by macrophages (Horie et al., 1993; Li et al., 1997). In the present series, these globules were observed in $9 \%$ of cases. Considering the intensity of trauma to the glandular tissue and the chronic nature of the lesion, we may speculate that the amount of extravasated material exceeds the capacity of macrophages to adequately phagocytose mucus and thus these structures are formed. Other rare findings in mucoceles are papillary synovial metaplasia-like changes (Chi et al., 2011). This morphological feature was not observed in the present series, although a few cases exhibited epithelioid histiocytes and pseudopapillary projections in granulation tissue.

Although Baurmash (2003) considers the presence of glandular tissue adjacent to oral mucoceles to be a rare finding, we observed salivary gland tissue adjacent to the lesions in $80 \%$ of cases, with some ducts partially lining the granulation tissue walls. This finding agrees with previous studies that attributed the formation of mucoceles to the rupture of excretory ducts and consequent extravasation of mucus into adjacent connective tissue ( $\mathrm{Li}$ et al., 1997; Hoque et al., 1998; Pesce et al., 2003; Frederic et al., 2008; Hayashida et al., 2010; Chi et al., 2011). Moreover, among the above described cases in which salivary gland tissue was present adjacent to the lesions, 3\% showed no significant alterations, whereas ectatic or metaplastic glandular ducts were observed in $76 \%$ and glandular tissue with inflammatory cells in $19 \%$. Other alterations included periductal fibrosis.

Mast cells originate from hematopoietic stem cells and respond to signals of the innate and adaptive immunity. A high mast cell 
density was observed in the granulation tissue wall, often close to blood vessels, where they contribute to maintenance of the inflammatory process since these cells, together with neutrophils and macrophages, modulate the recruitment, phenotype and function of lymphocytes involved in inflammatory responses (Metcalfe et al., 1997; Kashiwakura et al., 2004; Marshall, 2004; Mekori, 2004; Galli et al., 2005).

An interesting finding of the present study was the accumulation of mast cells in the capsular fibrous band, although no association was observed with the presence of collagen in the lesions. This finding might be explained by the mitogenic activity of mast cells for fibroblasts and their consequent participation in tissue remodeling (Sommerhoff, 2001). In addition, mast cells induce fibrosis and this probably may be due to the release of fibrogenic molecules such as TGF-beta (Tefferi, 2005). Overall, the present results suggest that the participation of mast cells in mucoceles seems to be more related to perpetuation of the existing inflammatory reaction and tissue remodeling involving fibrosis than to the different morphological features of the lesions.

Macrophages also play an important role in the tissue remodeling of chronic lesions by secreting modulators of inflammatory processes (Tonnesen et al., 2000; Mosser and Edwards, 2008). Similar to previous studies (Swelam et al., 2005; Chi et al., 2011), CD68-positive cells were detected in all oral mucocele specimens, both in granulation tissue and inside the cystic lumina. They could represent M1 macrophages probably as a result of phagocytosis of extravasated mucus still present in the tissue microenvironment. In addition to resident macrophages, another population of these cells is recruited in response to elevated levels of inflammatory mediators such as tumor necrosis factor (TNF), interferon-gamma (IFN-gamma), and interleukin-1 (IL-1). Macrophages become active and modulate cytokine production by fibroblasts, thus contributing to the formation of granulation tissue (Smith et al., 2006; Rodero and Khosrotehrani, 2010), synthesis of collagen and tissue remodeling although no association between these cells and collagen was observed in the present study.

MMP-1 is a collagen degrading enzyme found in areas of physiological or pathological tissue remodeling. In the present study, MMP-1 was detected in granulation tissue, particularly fibroblasts and inflammatory cells such as macrophages, demonstrating that these cells are important sources of this collagenase (Pesce et al., 2003; Ketelhuth and Bäck, 2011; Shi et al., 2012). This metalloproteinase was also detected in the capsular fibrous band since these proteins regulate matrix deposition (Gomez et al., 1997; Savage et al., 1997; Kostoulas et al., 1999; Parks, 1999). These findings suggest that MMP-1 participates in tissue remodeling throughout the stages of mucocele development.

MMP-9, or gelatinase $B$, is a protease that plays an important role in the degradation of the basement membrane (Pesce et al., 2003). In the present series, variable immunostaining for MMP-9 was seen in the extracellular matrix and fibroblasts and inflammatory cells of the granulation tissue, as well as in cells found in the lumina and capsular fibrous bands.

The presence of these MMPs in oral mucoceles has also been described by Swelam et al. (2005) and Hoque et al. (1998). In this respect, the present results suggest that MMP-1 and MMP-9 are important regulators of cell migration and matrix deposition, contributing to the development and progression of mucoceles. MMPs have been shown to play a key role in wound chronicity (Shi et al., 2012). This hypothesis seems to be supported by the fact that, together with tissue inhibitors of metalloproteinases (TIMPs), MMPs modulate cell migration, inflammation and angiogenesis, key events in the healing of chronic wounds and fibrous scars (Arumugam et al., 1999; Parks, 1999).

In the present study, all cases were CD34 positive, with variations in the mean number of positive cells. These findings demonstrate marked migration and mobilization of CD34-positive cells in oral mucoceles, probably as a result of injury to the salivary gland tissue, thus contributing to the development of the lesion. Swelam et al. (2005) also found CD34-positive cells in the lumina of retention cysts of the lower lip and suggested that the monocytemacrophage lineage is the main source for endothelial cells in these lesions. One important finding was that CD34-positive cells disappeared with decreasing distance from the cystic lumen, although some of these cells were still found in this compartment. Tissue remodeling of the lesions may be one explanation for the absence of these cells.

A synergistic action among different proteolytic enzymes and their inhibitors is necessary for the degradation of extracellular matrix components during angiogenic processes (Hoque et al., 1998; Pesce et al., 2003). In a study on MMP-9-deficient mice, gelatinase was a critical factor for the response to injury, with its absence delaying the inflammatory response and reducing VEGF levels. However, no changes in microvessel density were observed in wound extracts of these mice, a finding suggesting that other MMPs are able to compensate for the absence of MMP-9 in this model (Kyriades et al., 2009). The present results agree with those reported by Kyriades et al. (2009) since we found no association between MMP-9 and microvessel density or other components of the lesions studied. However, it is possible that MMP-1 and MMP-9 act synergistically with each other and also with other components necessary for lesion remodeling. Further studies using zymography should be able to clarify this aspect.

The involvement of MMPs in the degradation of collagen is another crucial prerequisite for angiogenic processes. The migration of endothelial cells and development of new capillaries depend not only on the presence of cells and cytokines, but also on the production and organization of extracellular matrix components. In the present study, picrosirius red staining was observed in most cases, with a predominance of mild and moderate fibrosis. Collagen is important for cell adhesion, chemotaxis and cell migration. The dynamic interaction of collagen with other cellular elements regulates tissue remodeling during growth, differentiation, morphogenesis and wound healing (Myllyharju and Kivirikko, 2004).

In the present study, a significant association was observed between mast cell density and MMP-1 expression. This result might be related to the ability of activated mast cells to induce the degradation of extracellular matrices through the activation of proMMPs by secreting serine proteases (tryptase and chymase) stored in their granules (Kovanen, 2009). This activation was demonstrated by Di Girolamo and Wakefield (2000) and Milne (2001) in endometrium, gingiva, synovial tissue, and human mast cell lineages, respectively.

According to Mosser and Edwards (2008), macrophages contribute to angiogenesis by secreting VEGF and by producing MMPs which degrade extracellular matrix components, processes that are important for the formation of new blood vessels. We observed an association between macrophages and MMP-1, in addition to the presence of MMP- 1 in these cells (Pesce et al., 2003). We may speculate that macrophages recruit MMP- 1 or activate this enzyme through the secretion of other proteases that activate MMPs. Although we found no significant difference between mast cells and CD34-positive vessels, we believe that these proteins are involved in the formation of mucoceles.

Finally, this study provided important insight into the demographic and histopathologic findings of oral mucoceles from a Brazilian sample. Although further studies with larger samples may be performed and a more diverse pool of cellular and extracellular components should be assessed, our results showed that the formation of oral mucoceles and the tissue remodeling seen in these lesions involve the migration and interaction of key 
cellular and extracellular matrix components. These biological events are orchestrated mainly by mast cells, macrophages, and MMP-1.

\section{Acknowledgments}

This study was supported by CNPq (Conselho Nacional de Desenvolvimento Científico e Tecnológico) and CAPES (Coordenação de Aperfeiçoamento de Pessoal de Ensino Superior).

\section{References}

Arumugam S, Jang YC, Chen-Jensen C, Gilbran NS, Isik FF. Temporal activity of plasminogen activators and matrix metalloproteinases during cutaneous wound repair. Surgery 1999;125:587-93.

Ata-Ali J, Carrillo C, Bonet C, Balaguer J, Peñarrocha MA, Peñarrocha M. Oral mucocele: review of the literature. J Clin Exp Dent 2010;2:10-3.

Baurmash HD. Mucoceles and ranulas. J Oral Maxillofac Surg 2003;61:369-78.

Chi AC, Lambert PR, Richardson MS, Neville BW. Oral mucoceles: a clinicopathologic review of 1824 cases, including unusual variants. J Oral Maxillofac Surg 2011;69:1086-93.

Chen JY, Wang WC, Chen YK, Lin LM. A retrospective study of trauma-associated oral and maxillofacial lesions in a population from southern Taiwan. J Appl Oral Sci 2010;18:5-9.

Coleman R. Picrosirius red staining revisited. Acta Histochem 2011;113:231-2.

Di Girolamo ND, Wakefield D. In vitro and in vivo expression of interstitial collagenase/MMP-1 by human mast cells. Dev Immunol 2000;7:131-42.

Enoksson M, Lyberg K, Moller-Westerberg C, Fallon PG, Nilsson $G$, Lunderius-Andersson C. Mast cells as sensors of cell injury through IL-33 recognition. J Immunol 2011;186:2523-8.

Frederic MK, Yamaai T, Mizukawa N, Kaneda Y, Katase N, Gunduz $\mathrm{M}$, et al. Expression of human $\beta$-defensin-1, -2 , and -3 in noninflamed pseudocyst, mucoceles. Oral Dis 2008;14:652-7.

Galli Sj, Nakae S, Tsai M. Mast cells in the development of adaptive immune responses. Nat Immunol 2005;6:135-42.

Gomez DE, Alonso DF, Yoshiji H, Thorgeirsson UP. Tissue inhibitors of metalloproteinases: structure, regulation and biological functions. Eur J Cell Biol 1997;74:111-22.

Hayashida AM, Zerbinatti DC, Baiducci I, Cabral LA, Almeida JD. Mucus extravasation and retention phenomena: a 24-year study. BMC Oral Health 2010;10:15.

Horie N, Shimoyama T, Ide F. Myospherulosis of the lower lip. Int J Oral Maxillofac 1993;22:234-5.

Hoque MO, Azuma M, Sato M. Significant correlation between matrix metalloproteinase activity and tumor necrosis factor$\alpha$ in salivary extravasation mucoceles. J Oral Pathol Med 1998;27:30-3.

Ide F, Kusama K. Myxoglobulosis-like change in a lower lip mucocele. Histopathology 2002;40:575-6.

Kashiwakura J, Yokoi H, Saito H, Okayama Y. T cell proliferation by direct cross-talk between OX40 ligand on human mast cells and OX40 on human T cells: comparison of gene expression profiles between human tonsillar and lung-cultured mast cells. J Immunol 2004;173:5247-57.

Ketelhuth Df, Bäck M. The role of matrix metalloproteinases in atherothrombosis. Curr Atheroscler Rep 2011;13:162-9.
Kostoulas G, Lang A, Nagase H, Baici A. Stimulation of angiogenesis through cathepsin $\mathrm{B}$ inactivation of the tissue inhibitors of matrix metalloproteinases. FEBS Lett 1999;455: 286-90.

Kovanen PT. Mast cells in atherogenesis: actions and reactions. Curr Atheroscler Rep 2009;11:214-9.

Kyriades TR, Wulsin D, Skokos EA, Fleckman P, Pirrone A, Shipley JM, et al. Mice that lack matrix metalloproteinase-9 display delayed wound healing associated with delayed reepithelization and disordered collagen fibrillogenesis. Matrix Biol 2009;28: 65-73.

Li TJ, Kitano M, Yoshida A, Iwashige Y, Yamashita S. Myxoglobulosis in an extravasation mucocele of the lower lip. J Oral Pathol Med 1997;26:342-4.

Li J, Chen J, Kirsner R. Pathophysiology of acute wound healing. Clin Dermatol 2007;25:9-18.

Marshall JS. Mast-cell responses to pathogens. Nat Rev Immunol 2004;4:787-99.

Mekori YA. The mastocyte: the "other" inflammatory cell in immunopathogenesis. J Allergy Clin Immunol 2004;114:52-7.

Metcalfe DD, Baram D, Mekori YA. Mast cells. Physiol Rev 1997;77:1033-79.

Milne AS. Co-localization of matrix metalloproteinase- 1 and mast cell tryptase in the human uterus. Mol Hum Reprod 2001;7:559-65.

Mosser DM, Edwards JP. Exploring the full spectrum of macrophage activation. Nat Rev Immunol 2008;8:958-67.

Myllyharju J, Kivirikko KI. Collagens, modifying enzymes and their mutations in humans, flies and worms. Trends Genet 2004;20:33-43.

Nico MMS, Park JH, Lourenço SV. Mucocele in pediatric patients: analysis of 36 children. Pediatr Dermatol 2008;25:308-11.

Parks WC. Matrix metalloproteinases in repair. Wound Repair Regen 1999;7:423-32.

Pesce C, Ciapasson A, Valente S, Passarello S. Tissue repair and remodelling in extravasation mucocele. Histopathology 2003;42:510-7.

Rodero MP, Khosrotehrani K. Skin wound healing modulation by macrophages. Int J Clin Exp Pathol 2010;3:643-53.

Romana-Souza B, Monte-Alto-Costa A. Cutaneous wound healing of stressed chronically mice is improved through cathecolamines blockade. Exp Dermatol 2010;19:821-9.

Savage FJ, Lacombe DL, Boulos PB, Hembry RM. Role of matrix metalloproteinases in healing of colonic anastomosis. Dis Colon Rectum 1997;40:962-70.

Shi L, Ramsay S, Ermis R, Carson D. In vitro and in vivo studies on matrix metalloproteinases interacting with small intestine submucosa wound matrix. Int Wound J 2012;9:44-53.

Smith JW, Gamelli RL, Jones SB, Shankar R. Immunologic responses to critical injury and sepsis. J Intensive Care Med 2006;21:160-72.

Sommerhoff CP. Mast cell tryptases, airway remodeling. Am J Respir Crit Care Med 2001;164:52-8.

Swelam W, Ida-Yonemochi H, Saku T. Angiogenesis in mucous retention cyst: a human in vivo-like model of endothelial cell differentiation in mucous substrate. J Oral Pathol Med 2005;34:30-8.

Tefferi A. Pathogenesis of myelofibrosis with myeloid metaplasia. J Clin Oncol 2005;23:8520-30.

Tonnesen MG, Feng X, Clark RA. Angiogenesis in wound healing. J Invest Dermatol Symp Proc 2000;5(40):6. 